\title{
Introduction of a skills boot camp for final year undergraduate medical students entering internship in General Medicine in a North Indian medical college: A pilot study
}

\author{
Nalin Kumar Mahesh', Niket Verma ${ }^{2, *}$, Charu Mohan ${ }^{3}$, Ashwin Mahesh $^{4}$, Puhup Verma $^{5}$, Rahul Mannan $^{6}$ \\ ${ }^{1}$ Professor, ${ }^{2}$ Assistant Professor, ${ }^{3}$ Associate Professor, ${ }^{4}$ Research Assistant, Dept. of General Medicine, Army College of Medical \\ Sciences, Delhi Cantt., New Delhi, ${ }^{5}$ Post Graduate Resident, Dept. of General Surgery, Santosh Medical College, Ghaziabad, \\ Uttar Pradesh, ${ }^{6}$ Professor, Dept. of Pathology, Sri Guru Ram Das Institute of Medical Sciences \& Research, Amritsar, \\ Punjab, India
}

*Corresponding Author:

Email: drniketverma@gmail.com

\begin{abstract}
Introduction: During internship students acquire basic clinical skills and hands on clinical experience. Although the interns are supposed to learn these clinical skills under supervision, this is not always possible. Even though the Medical Council of India, in its VISION 2015 Document has emphasised on "Early Clinical Exposure" and clinical training from first year, medical education in India remains highly oriented towards theoretical learning. Theoretical learning of clinical skills and procedures is not sufficient to handle the various clinical scenarios that the interns face everyday.

Materials and Methods: A 3 day 'Skills Boot Camp' was conducted in the Department of Medicine. The boot camp included skills from (and related to) the speciality of General Medicine. A total of 13 students who entered General Medicine for the first internship posting participated in the boot camp.

Results: All 13 participants showed an increase in their knowledge and confidence levels in the targeted skills. All faculty members agreed that after attending the skills boot camp the interns were able to perform their duties efficiently, displayed improved communication skills and were better prepared in dealing with difficult patients and angry relatives.

Conclusion: A skills boot camp which targets basic communication and clinical skills was well received by the interns and faculty alike. Both the interns and the faculty agreed that the skills boot camp should be incorporated as a permanent feature of internship and reported high overall satisfaction levels with the camp.
\end{abstract}

Keywords: Internship and residency, Curriculum, Clinical competence, Physician-patient relations.

\section{Introduction}

During internship students acquire basic clinical skills and hands on clinical experience. Although the interns are supposed to learn these clinical skills under supervision, this is not always possible, especially in busy hospitals and overworked departments. Sometimes the departments are not geared to train and monitor interns because they are pre-occupied with PG Training programmes. ${ }^{1,2}$

Interns often have to take autonomous decisions especially in the setting of emergency/trauma departments and face clinical scenarios they are ill equipped to handle. This new-found independence is stressful to interns and may pose a danger to patients. ${ }^{3-5}$

The MCI in its VISION 2015 document has emphasised on "Early Clinical Exposure" and advocated that clinical training should start in the first year, with a foundation course, focusing on communication, basic clinical skills and professionalism. However, medical education in India remains oriented towards theoretical learning and the care and treatment of admitted patients with lesser focus on teaching basic clinical skills or on out-patient care.

There is a wide gap in student's knowledge regarding clinical skills not covered in a traditional medical school curriculum which makes it difficult for the junior doctors to successfully navigate through internship. ${ }^{6}$ Despite improved curricula and emphasis on core skills, difficulties are faced during transition from medical students to interns ${ }^{7,8}$ Clinical Skills Boot Camps and Simulated Internship Courses help medical undergraduate students in transitioning to clinical work. $^{9-12}$ Students attending such boot camps have reported higher confidence, improved performance and better preparedness in the targeted domains. ${ }^{13-18}$ However, very few similar studies have been conducted in India. Most studies have suggested post-internship evaluation exams, compulsory rural postings, increasing PG seats etc. as methods to improve and strengthen the existing internship programme. ${ }^{19,20}$ The lone study that conducted a structured internship orientation programme focussed only on soft skills. ${ }^{10}$ The present study aims to bridge this gap and conduct a boot camp with emphasis both on soft skills and clinical skills.

\section{Aim}

To introduce a skills boot camp for improving the clinical and communication skills of interns to enable them to become competent Indian Medical Graduates and better doctors. 


\section{Materials and Methods}

A 3 day 'Skills Boot Camp' was conducted in the Department of General Medicine, Army College of Medical Sciences. The boot camp included skills from (and related to) the speciality of General Medicine. Students were taught using standardized patients to enable them to learn the skills in a stress free environment and without endangering the lives of real patients. This allows room for error without needing urgent correction even as it prepares the students to face sick patients during internship. ${ }^{21-23}$

The faculty was multi-disciplinary and was derived from the specialties of General Medicine, Cardiology, Pathology, Biochemistry, Microbiology, Pharmacology and Physiology.

The boot camp was held after the final professional exam of the MBBS 2013 batch on the first three days of internship. A total of 13 students who entered General Medicine for the first internship posting participated in the boot camp.

Prior to the boot camp, the participants were evaluated on the topics to be covered using a prevalidated, pre-camp multiple choice questionnaire. The boot camp concluded with an informal group discussion, post-camp questionnaire and survey to assess improvement in knowledge and to gather feedback from the participating interns. At the end of 2 months, feedback was also taken from the faculty members of the department under whom the interns had been posted during their rotation in General Medicine.

The Boot Camp was organized as follows -

\section{Day 1:}

Morning Session: (0800-0930 hrs.)

1. Familiarization with General Medicine OPD (30 mins.)

i. Familiarization with Medicine and allied superspeciality OPD's (Cardiology, Endocrinology, Neurology and Nephrology).

ii. Familiarization with various ancillary rooms e.g. ECG room for males and females, duty stations for interns, residents' duty room, nursing station, record room etc.

2. Familiarization with universal precautions (Medicine OPD and Medicine Wards 1 and 2 - 30 mins.) (Cardiac Cath Lab - 30 mins.)

i. Basic components and steps of universal precautions, chemical composition of alcohol based and alcohol free hand sanitizers.

ii. A demonstration showing the steps of universal precautions including hand washing, wearing gloves, masks, aprons, gum boots and caps was conducted by the faculty.

Afternoon Session: (1430-1600 hrs.)

1. Proper use of stethoscope and BP apparatus and accurate measurement of blood pressure $(30+15=$ 45 mins.) i. Topics - procedure for correct usage of Sphygmomanometer, dimension of various BP cuffs, palpatory and auscultatory methods of BP measurement, koratkoff sounds, auscultatory gap, mean BP, pulse pressure, baroreceptors in the human body, hypotension, hypertension, syncope.

ii. Followed by a 15 mins workshop in which 2 interns were randomly selected and asked to measure the blood pressure of 2 standardized patients.

2. Basic knowledge of various biochemical investigations routinely ordered in Medicine OPD including proper filling of investigation slips (45 mins.)

i. Topics - sample collection, routine investigations for estimating glucose, urea, creatinine, protein and electrolyte levels in serum and urine samples, common antiglycolytics and anticoagulants.

ii. The interns were shown how to fill the investigation slips properly and how to interpret reports. 2 sample reports were discussed in detail.

\section{Day 2}

Morning Session: (0800-0845 hrs.)

1. Basic knowledge of various pathological investigations routinely ordered in Medicine OPD including proper filling of investigation slips (45 mins.)

i. Topics - identification of vacutainers by colour coding, sample collection, common haematological tests, routine tests for malaria, dengue and chikungunya, thalassaemia, red cell distribution width (RDW), routine tests for iron deficiency anaemia including serum iron profile, use of RDW in microcytic hypochromic anaemia.

ii. The interns were shown how to fill the investigation slips properly and how to interpret reports. 2 sample reports were discussed in detail.

Afternoon Session: (1400-1530 hrs.)

1. Basic knowledge of various microbiological investigations routinely ordered in Medicine OPD including proper filling of investigation slips (45 mins.)

i. Topics - sample collection, different culture media routinely used in hospital laboratory, tests for screening and confirming HIV infection, Mycobacterium tuberculosis, Gene X-Pert, culture and sensitivity tests on urine and stool samples

ii. The interns were shown how to fill the investigation slips properly and how to interpret reports. 2 sample reports were discussed in detail.

2. Prescription writing as per latest $\mathrm{MCI}$ regulations and rational drug prescription $(30+15=45$ mins. $)$

i. Topics - parts of a prescription, latest MCI norms for prescription writing, common drug contraindications, side effects of long term steroid therapy, irrational and rational drug combinations, rational drug therapy 
ii. Followed by a 15 mins workshop in which 2 interns were randomly selected and asked to write sample prescriptions for a standardized patient. Strengths and weaknesses of both prescriptions were then discussed with all the interns.

\section{Day 3}

Morning Session: (0800-0900 hrs.)

1. Understanding the importance of interpersonal relationships with allied health staff (30 mins.)

2. Understanding the role of better communication skills to improve doctor-patient relationship especially in OPD and emergency setting (30 mins.)

Afternoon Session: (1400-1600 hrs.)

1. Importance of communication skills in dealing with angry patients/attendants and difficult colleagues (1 hour)

i. 2 Role play sessions were conducted. 2 scenarios were depicted in each session.

ii. The first session dealt depicted the importance of good doctor-patient relationship. The second session depicted the importance of good interpersonal relationships between members of a healthcare team.

2. Informal group discussion, post-camp questionnaire and survey to assess improvement in knowledge and to gather feedback. (1 hour)

\section{Results}

1. A pre-camp multiple choice questionnaire (Total 32 questions) was administered to the 13 interns. The same questionnaire was administered to all 13 interns after the camp concluded. The results were compared to assess any change in knowledge levels. All 13 participants showed a significant increase in their knowledge levels ( $p$ value $<.05$ ). Participants 3, 10 and 11 showed greatest percentage increase in marks and therefore their knowledge levels were most benefitted by the skills boot camp.

2. Section A of the student feedback questionnaire consisted of 19 questions based on a 5 point Likert Scale.

i. All 13 participants $(100 \%)$ strongly agreed that the instructors were knowledgeable about their subject. 11 interns $(84.6 \%)$ strongly agreed that the instructors were prepared to facilitate the boot camp. Only 8 interns (61.5\%) strongly agreed that the instructors encouraged participation from all students while the remaining $5(38.5 \%)$ somewhat agreed. (Fig. 1)

ii. There was a general agreement among the participants that their confidence levels have increased in all the covered skills. The only disagreement is regarding the statement that attending the skills boot camp increased confidence levels in using a stethoscope, to which 1 intern strongly disagreed. (Fig. 2)

iii. 12 out of 13 interns $(92 \%)$ strongly agreed with the statement that they will recommend the boot camp to their fellow batchmates. 11 interns $(85 \%)$ strongly agreed that the training environment was safe and the objectives of the camp were clearly defined. When asked whether the boot camp met their goals and expectations, 8 interns (61.5\%) strongly agreed, $3(23 \%)$ somewhat agreed and 2 (15.4\%) remained neutral. (Fig. 3)

3. Section $B$ of the student feedback questionnaire consisted of 3 Yes/No questions. All 13 interns $(100 \%)$ agreed that the skills boot camp was an effective way to prepare students for internship. Similarly, when asked whether the skills boot camp should be incorporated as a permanent feature of internship, all $13(100 \%)$ marked 'Yes'. When asked whether they were satisfied with the quality of training imparted, 11 interns (85\%) agreed.

4. Section B also consisted of 2 open ended questions.

i. 7 interns (54\%) came up with suggestions for additional topics that should be covered during the camp. 1 intern suggested adding a hands-on workshop for teaching sample collection. 1 intern suggested a session on minor procedures conducted in medicine wards. 2 interns suggested additional emphasis on soft skills. 1 intern suggested a discussion on the medicolegal aspects of clinical practice and the medicolegal issues they may face during their training. 1 intern suggested adding a session on emergency medicine and treatment of conditions like MI and status asthmaticus. Finally, 1 intern suggested the teaching of and about special investigations without specifying what he/she meant by 'special investigations'.

ii. In the second question, the interns were asked if they had any other suggestions and comments. 6 interns (46\%) answered this question. 2 interns suggested conducting the camp before the start of internship to better prepare them from day 1 of internship. 1 intern wanted a longer session on prescription writing. 1 intern appreciated the demonstration on universal precautions but wanted that the interns should be allowed hands on training for the same. 2 interns praised the camp and felt that the camp was helpful and beneficial for the interns. Some suggestions given by the participants were as follows -

a. "The skills camp should include hands-on training in sample collection"

b. "Common procedures done in medicine wards e.g. bandaging should also be taught"

c. "Regarding the soft skills section....instead of faculty members enacting a simulated scenario, I feel that doing this demonstration in a ward with real patients will be way more helpful" 
d. "Some common topics from emergency medicine like MI and status asthmaticus and their treatment should also be included"

5. Section $\mathrm{C}$ of the student questionnaire asked the interns to grade their overall satisfaction with the skills boot camp on a scale of 1 to 10 (1=highly unsatisfied; 5=neither satisfied nor unsatisfied; $10=$ highly satisfied). 4 participants $(31 \%)$ gave 10 points, 5 participants $(38 \%)$ gave it 9 points and 4 participants $(31 \%)$ gave it 7 points.

6. The faculty feedback form was administered to 6 faculty members from the department of General Medicine under whom the interns were posted during their rotation in medicine. There was a strong sense of agreement among faculty members that after attending the skills boot camp, the interns display better correlation between the theoretical, clinical and practical aspects of General Medicine ( 5 out of 6 agree), are able to perform their duties efficiently (5 out of 6 agree), display improved communication skills (all 6 agree) and are better prepared in dealing with difficult patients and angry relatives (4 out of 6 agree) (Fig. 4). 5 faculty members agree that implementation of the camp was helpful in developing good rapport between interns and allied healthcare staff while all faculty members unanimously agree that the camp was an effective way to prepare students for internship (Fig. 5). All 6 agreed that the camp should be incorporated as a permanent feature of internship.

7. Section B of the faculty feedback form also consisted of 3 open ended questions.

i. On being asked about the appropriate duration of the camp, $5(83 \%)$ agreed that 3 days were appropriate whereas 1 faculty member (17\%) felt that the boot camp should be spread over 4 days, with 1 day being solely dedicated to CPR training.

ii. All faculty members (100\%) suggested CPR as an additional topic both for discussion and for handson training of interns. Additionally, 2 faculty members $(33.3 \%)$ suggested that the session on universal precautions should include a discussion on hospital acquired and iatrogenic infections and their prevention.

iii. In the third question, faculty members were asked for any other suggestions and comments. All faculty members were appreciative of the new initiative. 1 faculty member $(16.7 \%)$ advocated making the boot camp a permanent feature of internship. 2 faculty members (33.3\%) suggested incorporating guided visits to the hospital laboratories. Some suggestions and comments received from the faculty are presented below.

a. "The boot camp should become a permanent feature of internship in the college'

b. 'Interns must visit the biochemistry, pathology and microbiology laboratories of the hospital to better understand the basis of common tests and the interpretation of reports",

c. "Excellent work!! Keep it up!!"

d. "I wish we had something like this when we joined internship"

8. Section $\mathrm{C}$ of the questionnaire asked the faculty members to grade their overall satisfaction with the skills boot camp on a scale of 1 to 10 (1=highly unsatisfied; $10=$ highly satisfied). 4 faculty members rated their satisfaction level at 9 whereas 2 faculty members were highly satisfied and rated their overall satisfaction at 10 .

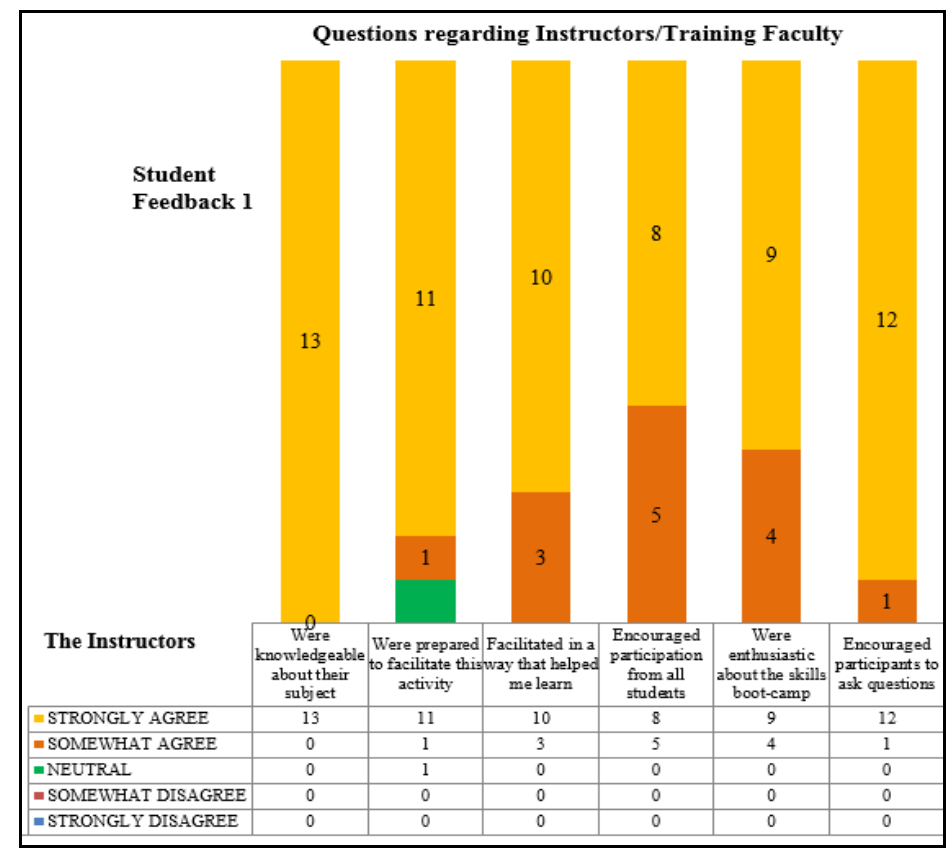

Fig. 1 


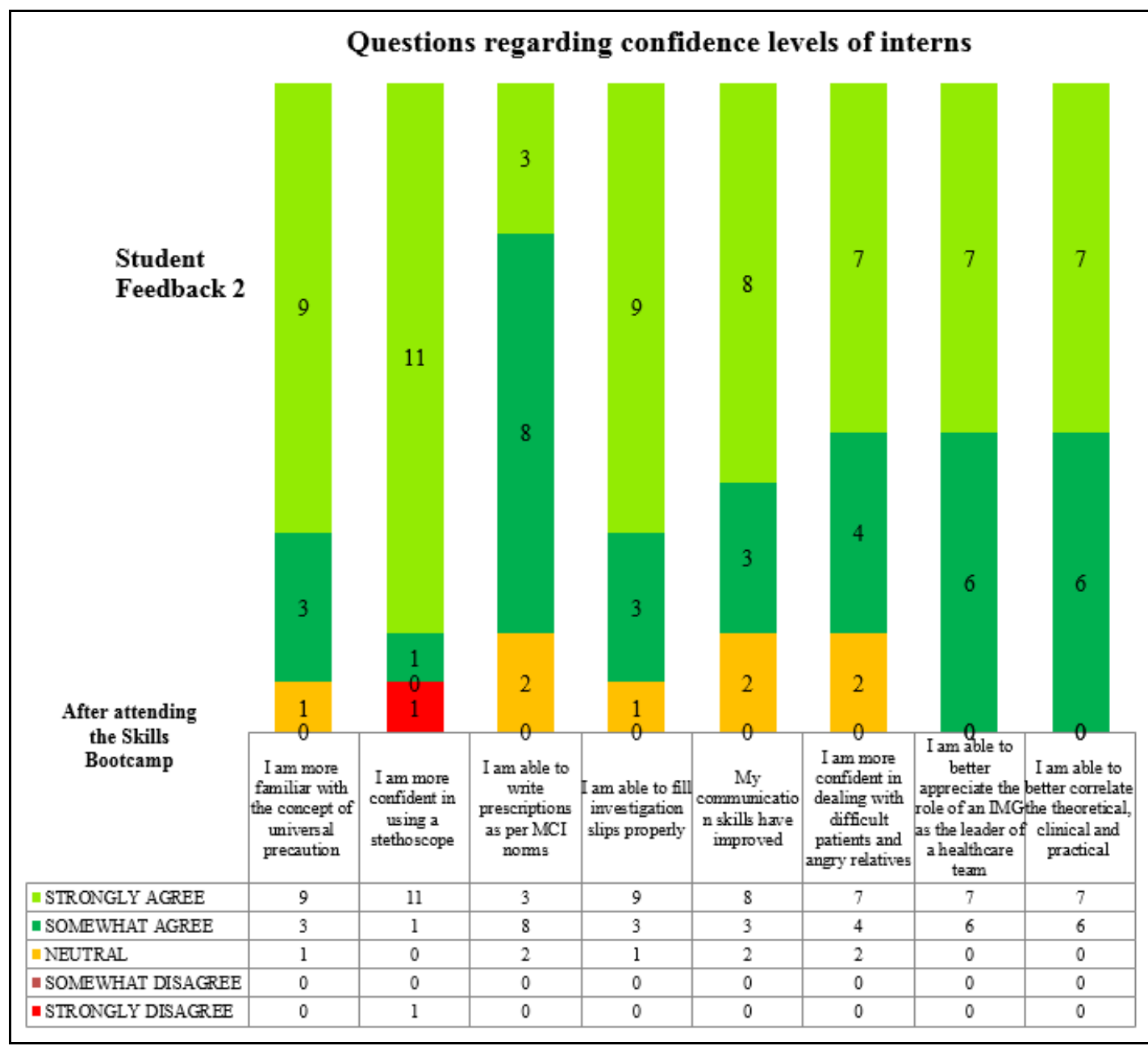

Fig. 2

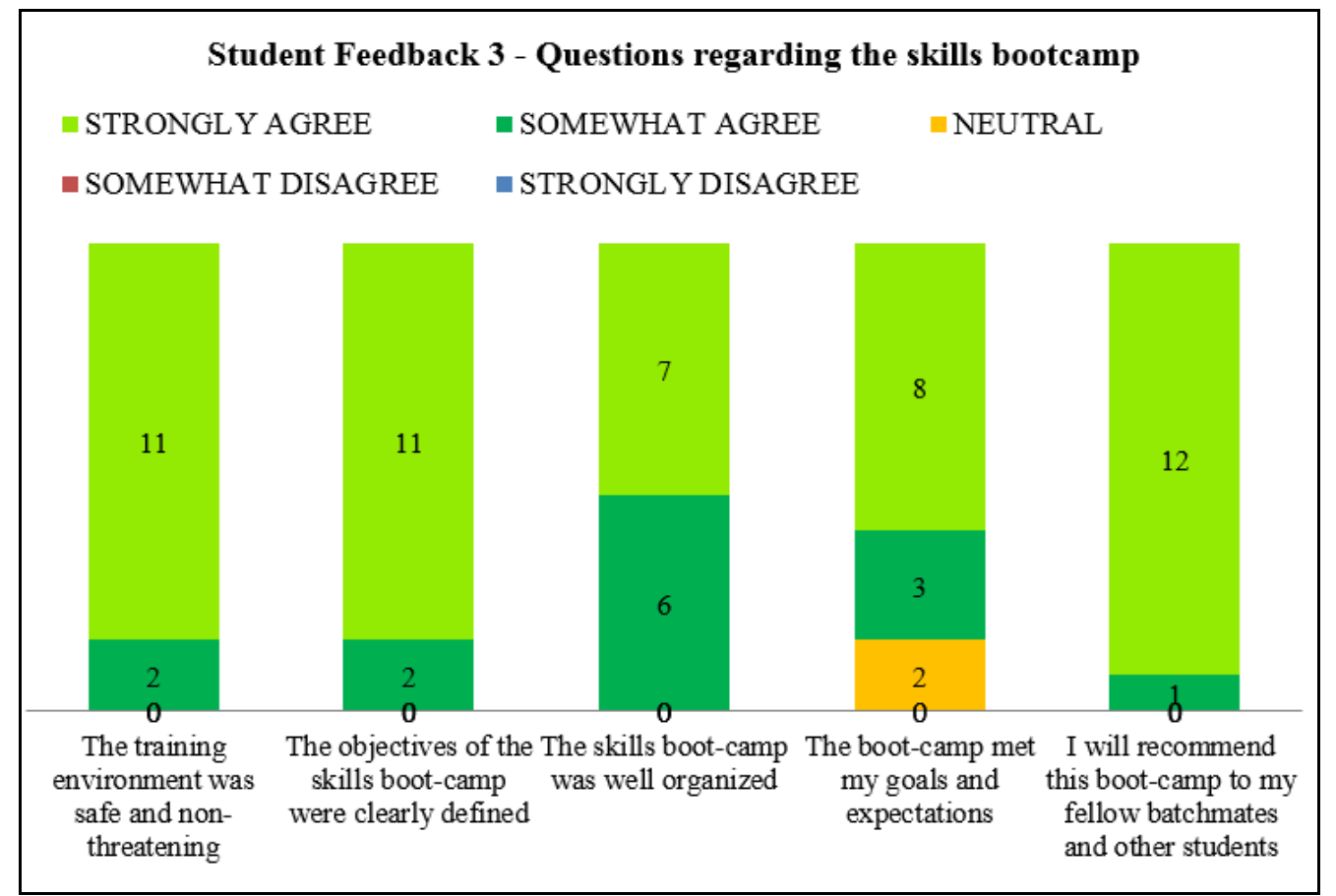

Fig. 3 


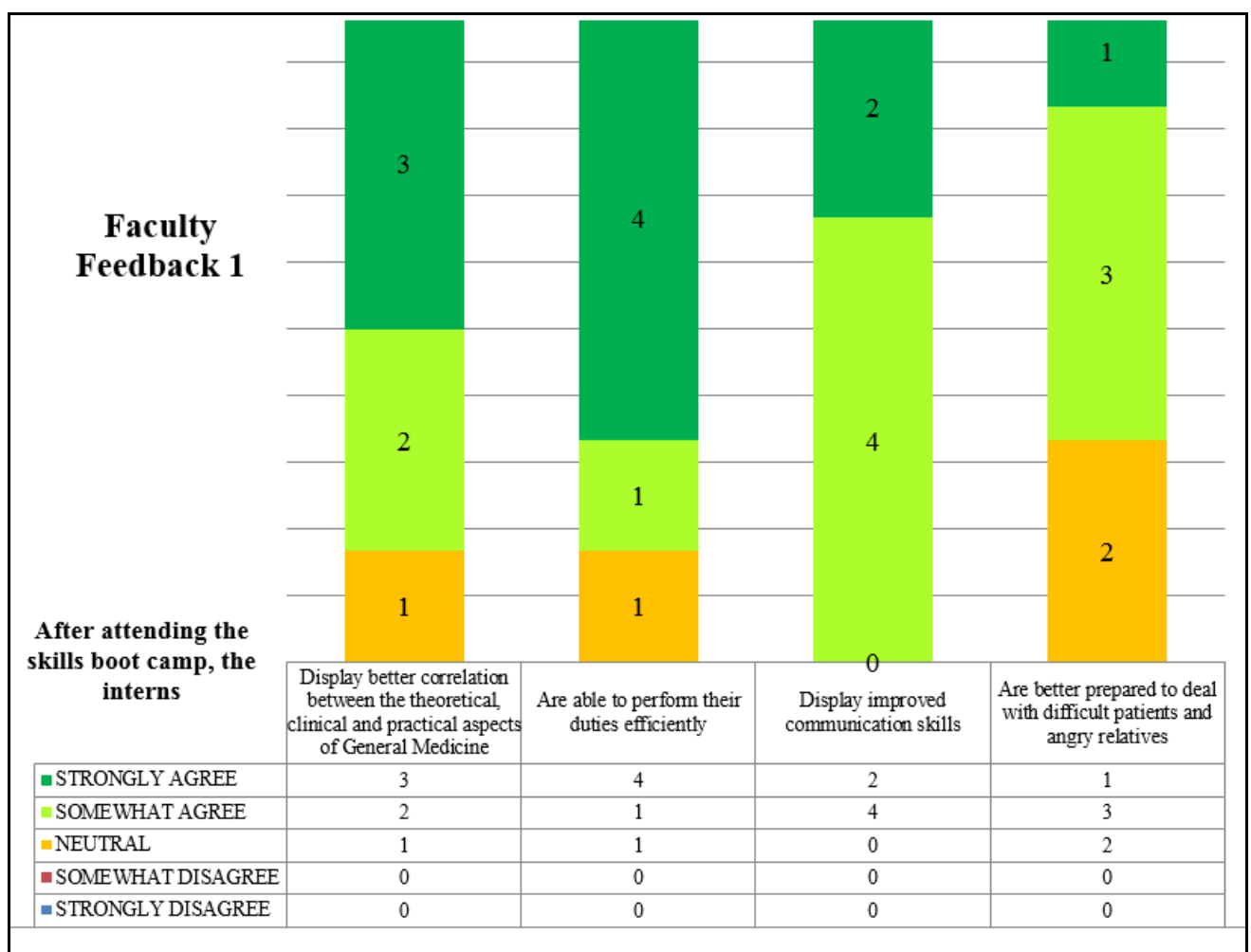

Fig. 4

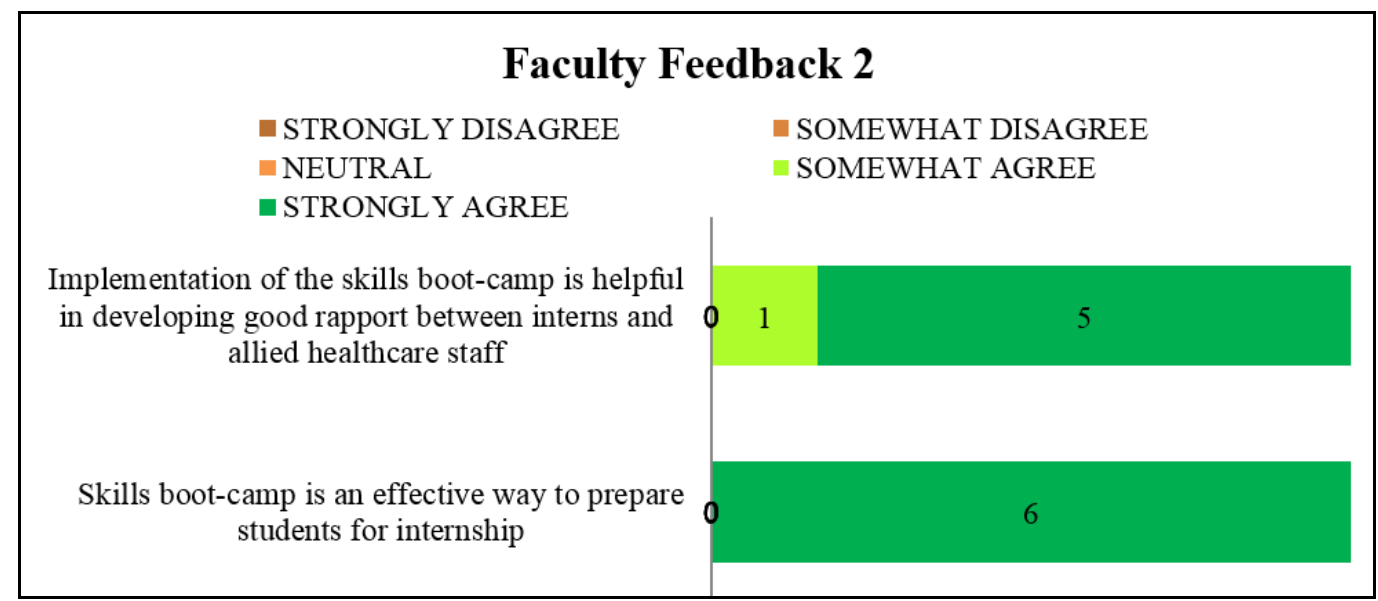

Fig. 5

\section{Discussion}

The term boot-camp has traditionally been used to refer to the initial instruction of newly recruited military personnel. Such training is both physically and psychologically intensive and is aimed at preparing the new recruits for the demands of military employment.

Skills boot camps are becoming increasingly common in medical colleges across the world, although they are mainly targeted at doctors entering first year of post-graduation. A news report published last year on the website of the Association of American Medical Colleges titled 'Boot Camps Prepare Medical Students for the Rigors of Residency' is a testament both to the popularity of such camps in USA and their usefulness to interns and post-graduate students. ${ }^{24}$ Recently, Israel has become one of the first countries in the world to make skills boot camps mandatory for all graduating doctors. ${ }^{25}$

The present study aimed at introducing such a skills boot-camp for final year undergraduate medical students entering internship. All 13 participants showed a statistically significant increase in their knowledge levels of the selected topics from before to after the conduct of the skills boot camp. Similar increase in knowledge levels has been reported in previous studies. ${ }^{26,27}$ There was a general agreement among the participants that their confidence levels increased in all 
the skills covered during the boot camp. 12 out of 13 interns $(92 \%)$ strongly agreed to recommend the boot camp to their fellow batchmates. 11 interns $(85 \%)$ strongly agreed that the training environment was safe and the objectives of the camp were clearly defined. When asked whether the boot camp met their goals and expectations, 8 interns $(61.5 \%)$ strongly agreed. All 13 interns (100\%) agreed that the skills boot camp is an effective way to prepare students for internship and it should be incorporated as a permanent feature of internship. Similar results have been reported by Lamba et al. ${ }^{28}$ and Omlor et al. ${ }^{29}$ Finally, the interns reported high levels of overall satisfaction with the skills boot camp.

Faculty members overwhelmingly agreed that after attending the camp, interns performed duties efficiently, were better prepared to deal with angry patients and relatives and developed good rapport with allied healthcare staff. All faculty members agreed that the boot-camp was an effective way to prepare students for internship and it should be incorporated as a permanent feature of internship. Finally, the faculty members reported high levels of satisfaction with the skills boot camp. Similar findings have been reported by Krajewski et al. among others. ${ }^{30}$

\section{Conclusions}

1. Skills boot camps enable smooth transition of medical students to interns and greatly improve both knowledge and confidence levels of interns.

2. Interns having mastery over basic clinical skills will perform their duties effectively and in turn become better doctors. They will be able to support the overburdened postgraduate residents and clinical specialists thus improving health standards and health indicators across the country.

3. Improved communication skills will reduce the communication gap between doctors and patients/attendants thereby reducing the incidence of physical violence against doctors. Such skills will also enable interns to work in synergy with other allied healthcare staff allowing them to become efficient leaders of healthcare teams in keeping with the vision of the Medical Council of India.

4. Involvement of non-clinical and para-clinical departments in the training of interns will reduce the burden on the clinical specialists.

\section{References}

1. Simon, H.H. Medical education in India. Health And Population-Perspectives and Issues. 1989;12:102-126.

2. Vaiyda, N.K. Medical education and primary health care. Indian Journal of Community Medicine. 1992;17:11-14.

3. Morgan R, Westmoreland C. Survey of junior hospital doctors' attitudes to cardiopulmonary resuscitation. Postgrad Med J. 2002;78:413-415.

4. Hayes CW, Rhee A, Detsky ME, Leblanc VR, Wax RS. Residents feel unprepared and unsupervised as leaders of cardiac arrest teams in teaching hospitals: a survey of internal medicine residents. Crit Care Med. 2007;35:1668-1672.

5. Scott G, Mulgrew E, Smith T. Cardiopulmonary resuscitation: attitudes and perceptions of junior doctors. Hosp Med. 2003;64:425-428.

6. Jenny Castillo, Jared Kutzin, Kathleen Agoglia, Patricia Janicke, Zachary Milligan and Jack Scott Journal of Medical Education and Curricular Development Volume $4: 1-4$.

7. Jones A, McArdle PJ, O'Neill PA. How well prepared are graduates for the role of pre-registration house officer? A comparison of the perceptions of new graduates and educational supervisors. Med Educ. 2001;35(6):578-84.

8. Nelson MS, Traub S. Clinical skills training of U.S. medical students. Acad Med. 1993;68(12):926-8.

9. $\quad$ P B Goodfellow, MB FRCS and P Claydon, MB ChB. Students sitting medical finals - ready to be house officers? J R Soc Med. 2001;94(10):516-520. PMCID: PMC1282206

10. Goel A, Venkat R, Kumar A, Adkoli BV, Sood R. Structured internship orientation programme for undergraduate students: easy transition to clinical work. Natl Med J India. 2010;23(3):160-2.

11. Jenny Castillo, Jared Kutzin, Kathleen Agoglia, Patricia Janicke, Zachary Milligan and Jack Scott. An Innovative Clinical Skills "Boot Camp" for Dental Medicine Residents. Journal of Medical Education and Curricular Development. 4:1-4.

12. Laack, Torrey A, Newman, James S, Goyal, Deepi G, Torsher, Laurence C. A 1-Week Simulated Internship Course Helps Prepare Medical Students for Transition to Residency Simulation in Healthcare: The Journal of the Society for Simulation in Healthcare. 2010;5(3):127-132 doi: 10.1097/SIH.0b013e3181cd0679

13. Sangeeta Lamba, Bryan Wilson, Brenda Natal, Roxanne Nagurka, Michael Anana, and Harsh Sule.A suggested emergency medicine boot camp curriculum for medical students based on the mapping of Core Entrustable Professional Activities to Emergency Medicine Level 1 milestones. Adv Med Educ Pract. 2016;7:115-124. Published online 2016 Mar 1. doi: 10.2147/AMEP.S97106 PMCID: PMC4780742

14. Ramsey Ataya, BS, Rahul Dasgupta, BS, Rachel Blanda, BS, Yasmin Moftakhar, BS, Patrick G. Hughes, DO, and Rami Ahmed, DO. Emergency Medicine Residency Boot Camp Curriculum: A Pilot Study. West J Emerg Med. 2015;16(2):356-361. Published online 2015 Mar 17. doi:5811/westjem.2015.1.23931 PMCID: PMC4380396

15. Fabiana Ortiz Figueroa, Yasmin Moftakhar, Arthur L Dobbins IV, Ramisha Khan, Rahul Dasgupta, Rachel Blanda, Tiffany Marchand, and Rami Ahmed. Trauma Boot Camp: A Simulation-Based Pilot Study. Cureus. 2016;8(1):e463. Published online 2016 Jan 20. doi: 10.7759/cureus.463. Monitoring Editor: Alexander Muacevic and John R Adler

16. Alice A Min, Lisa R Stoneking, Kristi H Grall, and Karen Spear-Ellinwood. Implementation of the Introductory Clinician Development Series: an optional boot camp for Emergency Medicine interns. Adv Med Educ Pract. 2014;5:275-279. Published online 2014 Aug 25. doi:10.2147/AMEP.S67239

17. Okusanya OT, Kornfield ZN, Reinke CE, Morris JB, Sarani B, Williams NN, Kelz RR. The effect and durability of a pregraduation boot camp on the confidence of senior medical student entering surgical residencies. $J$ Surg Educ. 2012;69(4):536-43. doi: 10.1016/j.jsurg.2012.04.001 
18. Rebekah Burns, Mark Adler, Karen Mangold, and Jennifer Trainor. A Brief Boot Camp for 4th-Year Medical Students Entering into Pediatric and Family Medicine Residencies Cureus. 2016;8(2):e488. Published online 2016 Feb 9. doi: 10.7759/cureus.488

19. Anand Kumar. Withering Internship Training In India. Indian J Surg. 2011;73(3):171-172. Published online 2011 Apr 6. doi: 10.1007/s12262-011-0241-6.

20. Bansal RK. Need for strengthening of internship (rotatory housemanship) training in India. Educ Health (Abingdon). 2004;17(3):332-8.

21. Gordon JA, Wilkerson WM, Shaffer DW, Armstrong EG. "Practicing" medicine without risk: students' and educators' responses to high-fidelity patient simulation. Acad Med. 2001;76:469-472.

22. Rosenthal ME, Adachi M, Ribaudo V, Mueck JT, Schneider RF, Mayo PH. Achieving housestaff competence in emergency airway management using scenario based simulation training: comparison of attending vs housestaff trainers. Chest. 2006;129:14531458.

23. Issenberg SB, McGaghie WC, Hart IR, et al. Simulation technology for health care professional skills training and assessment. JAMA 1999;282:861-866

24. Kim Krisberg. Boot Camps Prepare Medical Students for the Rigors of Residency. AAMC NEWS. Website. https://news.aamc.org/medical-education/article/bootcamps-prepare-medical-students-rigors-residen/. Accessed January 28, 2018.

25. Sa'ar Minha, Daphna Shefet, Doron Sagi, Haim Berkenstadt, Amitai Ziv. "See One, Sim One, Do One"A National Pre-Internship Boot-Camp to Ensure a Safer "Student to Doctor" Transition. PLoS One. 2016;11(3):e0150122. Published online 2016 Mar 2. doi: 10.1371/journal.pone.0150122

26. Fernandez GL, Page DW, Coe NP, Lee PC, Patterson LA, Skylizard L, St Louis M, Amaral MH, Wait RB, Seymour NE. Boot cAMP: educational outcomes after 4 successive years of preparatory simulation-based training at onset of internship. J Surg Educ. 2012;69(2):242-8. doi: 10.1016/j.jsurg.2011.08.007.

27. Cohen ER, Barsuk JH, Moazed F, Caprio T, Didwania A, McGaghie WC, Wayne DB. Making July safer: simulation-based mastery learning during intern boot camp. Acad Med. 2013;88(2):233-9. doi: 10.1097/ACM.0b013e31827bfc0a.

28. Lamba S, Wilson B, Natal B, Nagurka R, Anana M, Sule $\mathrm{H}$. A suggested emergency medicine boot camp curriculum for medical students based on the mapping of Core Entrustable Professional Activities to Emergency Medicine Level 1 milestones. Adv Med Educ Pract. 2016;7:115-24. doi: 10.2147/AMEP.S97106. eCollection 2016.

29. Omlor RL, Watkins FS, Lawlor JS, Lovato JF, Fino NF, Atkinson HH. Intern Boot Camp: Feasibility and impact of a 1-hour session to ensure graduating medical student competency in falls risk assessment. Gerontol Geriatr Educ. 2017;38(3):346-353. doi: 10.1080/02701960.2015.1115982.

30. Krajewski A, Filippa D, Staff I, Singh R, Kirton OC. Implementation of an intern boot camp curriculum to address clinical competencies under the new Accreditation Council for Graduate Medical Education supervision requirements and duty hour restrictions. JAMA Surg. 2013;148(8):727-32. doi: 10.1001/jamasurg.2013.2350. 